\title{
O Espaço da Ficção e os Limites do Sentido
}

Janine Resende Rocha ${ }^{1}$

RESUMO: Este artigo propõe uma reflexão sobre as condições de emergência do sentido, reflexão que demanda aqui a pesquisa de dois temas: a hermenêutica do texto literário e o papel do leitor diante desse texto, pensados a partir do romance $O$ processo, de Franz Kafka.

PALAVRAS-CHAVE: Hermenêutica literária, leitor, sentido, estatuto do ficcional, Franz Kafka, espaço.

ABSTR ACT: This paper intends to reflect on the conditions of emergence of meaning, which demands the research of two themes: the hermeneutics of the literary text and the reader's role before the text; themes that will be analyzed through the novel The trial, by Franz Kafka.

KEYWORDS: Literary hermeneutics, reader, meaning, status of the fictional, space, Franz Kafka.

O texto literário promove um enredamento do sentido, à maneira da mensagem imperial transmitida pelo imperador, no seu leito de morte, a um súdito. Na pequena narrativa intitulada “Uma mensagem imperial”, de Franz Kafka, depois de ouvir o último comunicado do imperador, o súdito não consegue sair do palácio, apesar da destreza e dos esforços empenhados, permanecendo nos seus aposentos. Mesmo que conseguisse deixá-los, o súdito teria que percorrer pátios, outros palácios e escadas ao longo de milênios.

Nos textos de Kafka há reiteradamente um espaço inacessível - seja no momento de entrada, seja no de saída -, como exemplificam o romance $O$ castelo, o capítulo "Na catedral", de $O$ processo, e o conto "Uma mensagem imperial". Graças à caracterização de um espaço vedado, sobressalta-se a impossibilidade de se conhecer uma mensagem ou os princípios que regem a administração do mundo criado. Essa impossibilidade problematiza, por consequência, o sentido a ser composto pelo leitor, já que ela acaba por predicar o texto com um caráter enigmático. O estranhamento produzido pelo texto de Kafka, que dá o tom da recepção crítica à sua obra, pode ser devido, em parte, à constituição do espaço - cujos atributos intercalam o interditado, inalcançável, insólito, labiríntico, precário, imprevisto ou ambivalente. Nesses termos, a assimetria, remetida à palavra e à forma de expressão, seria garantida pela disposição espacial, que, por sua vez, implica o obstáculo ao conteúdo.

A interrupção espacial em Kafka mostra como o sentido exacerba dois aspectos consideravelmente avessos entre si: o estímulo e o obstáculo à compreensão e à interpretação do texto. O texto literário convida o leitor a produzir e a atribuir sentido, pois o texto existe enquanto "mera virtualidade" (ISER, 1996, p. 123) e depende do leitor para ser atualizado. Porém, o texto também oferece resistências, uma vez que, ao protagonizar essa atualização, o leitor deve compor, por meio do seu imaginário, um mundo que é em tese diferente do mundo empírico. Na composição desse mundo outro, o leitor deve ainda ter esmero para completar as omissões narrativas apresentadas pelo texto.

${ }^{1}$ Doutoranda em Literatura Comparada da Universidade Federal de Minas Gerais - Belo Horizonte. Desenvolve pesquisa sobre hermenêutica literária a partir das teorias de Mikhail Bakhtin e de Wolfgang Iser. Bolsista CAPES. Contato: janine_rocha@hotmail.com. 


\section{O espaço da ficção em Kafka: hermenêutica literária e os limites do sentido}

No capítulo "Na catedral", do romance $O$ processo, a chegada de um camponês à entrada da lei perfaz uma espacialidade que define o interior e o exterior da lei. Diante dessa entrada, o camponês descobre contrariado que o preceito segundo o qual a lei deve estar ao alcance de todos não se confirma. Na sua acepção espacial, essa negativa significa que o camponês não poderá adentrar o interior da lei, resguardado por porteiros poderosos que personificam obstáculos intransponíveis. Em vão, o camponês permanece sentado do lado de fora da lei e na companhia de um dos porteiros até o fim da vida. No desdobramento do capítulo mencionado, há uma sequência de interpretações conflitantes para essa historieta do camponês, que averiguam, entre outros detalhes, se tal porteiro enganou o camponês, se cumpriu o seu dever ou se foi enganado.

Na medida em que as opiniões sobre o caráter, as palavras e as atitudes do porteiro se sucedem, elas concebem um outro texto que pressupõe a condição criativa do intérprete, fundamento para a diversidade das interpretações que o texto original recebe, apesar de permanecer inalterado. Reconhecer a condição criativa do intérprete implica o abandono de uma concepção que almeja o sentido imanente ao texto - e, como a passagem de Kafka mostra, esse reconhecimento leva ao questionamento sobre os limites do intérprete diante do texto, que o alertariam na hipótese de estar modificando a história. Entretanto, conforme a passagem aventa, a acentuação desses limites é devedora de fatores externos ao texto, como a opinião de outros intérpretes ou de uma autoridade legitimadora. O sacerdote, interlocutor de Josef $\mathrm{K}$. na catedral, pretende exercer essa autoridade, e sugere que tais opiniões precisam se apresentar como sistemas argumentativos convincentes para que possam ser validadas.

A literatura de Kafka inspira um debate em que a interpretação e as propriedades do ficcional encontram-se relacionadas. Segundo Luiz Costa Lima avalia na obra Limites da voz, Kafka é um autor dos mais importantes para se desacreditar a "estabilidade semântica da obra de ficção" (1993, p. 61), estabilidade a que corresponde a expectativa pela interpretação verdadeira dessa obra. Na esteira dessa avaliação, a passagem de $O$ processo anteriormente lembrada exemplifica a "instabilidade semântica que atravessa o texto kafkiano" (COSTA LIMA, 1993, p. 66), por ilustrar a "impossibilidade de aprisionar-se a letra em um único sentido" (COSTA LIMA, 1993, p. 127).

Na contemporaneidade, o debate voltado para o sentido e o leitor grava os limites do sentido como um impasse incontornável, circunscrição que aponta necessariamente para a autonomia do leitor diante do texto literário. Na configuração desse debate, o sujeito interpretante - isto é, o leitor - conquistou um destaque teórico mediante a objeção ao "campo hermenêutico" (GUMBRECHT, 1998, p. 139-140), campo que pressupõe uma congruência entre a expressão do autor e o sentido atribuído ao texto pelo intérprete. Paralelamente, deve ser sublinhado também como a ausência de diretrizes fixas e de valores hegemônicos que caracteriza o cenário teórico contemporâneo dificulta a definição de limites para o desempenho do leitor. Sendo assim, o enredamento do sentido torna-se ainda mais tortuoso com a objeção ao "campo hermenêutico". 
A hermenêutica não deve ser pensada como uma via de domesticação do sentido, que pretende exaurir todas as camadas semânticas do texto e que contraria a contingência. Se avaliada sob uma concepção ampla, a hermenêutica pode tratar de questões pertinentes ao sentido e à diversidade de possibilidades semânticas admitidas por um mesmo texto, sem deixar de pressupor uma decidibilidade. O gesto hermenêutico contempla um variado campo semântico, do qual, além da hermenêutica, fazem parte interpretação, exegese e leitura. Segundo Wolfgang Iser distingue no livro The range of interpretation,

[...] hermeneutic is just a prominent genre dealing basically with texts that are opened up for understanding. But when it comes to interpreting something that is neither textual nor scripted, such as culture, entropy, or even the incommensurable, the procedures of interpretation are bound to change. ${ }^{2}$ (ISER, 2000, p. ix)

Apesar da distinção, Iser se refere à hermenêutica do texto literário valendo-se da interpretação, sugestão de que ambas as expressões autorizam alguma permuta.

A argumentação do autor frisa dois pontos básicos, concentrados na seguinte afirmação: "Interpretation is an act of translation, the execution of which depends on the subject matter to be interpreted as well as on the context within which the activity takes place"3 (ISER, 2000, p. 145). Esses pontos enfatizam características fundamentais do sentido: 1. ele resulta na produção de objeto distinto da matéria interpretada; 2. sofre variações de acordo com o objeto interpretado e com a contingência do sujeito interpretante. Portanto, uma teorização sobre a hermenêutica do texto literário concebe aspectos que podem não estar presentes na hermenêutica jurídica ou psicanalítica, por exemplo. Essa diversidade de aspectos - base do que Iser designa como range of interpretation - também pode ser observada através da variação conceitual com a qual a atividade hermenêutica ou interpretativa é distinguida numa única área disciplinar. Mesmo num fulcro disciplinar específico - como o dos estudos literários -, o complexo emaranhado de matizes e de perspectivas pertinentes ao sentido faz da hermenêutica um exemplo de umbrella term, ou seja, de um termo que comporta um amplo espectro conceitual. Assim, o gesto hermenêutico perante o enunciado literário pode ser entendido de maneiras variadas, com a possibilidade de haver o triunfo de uma maneira sobre as outras num dado contexto.

Por dizer respeito "a certos problemas peculiares que caracterizam o 'procurar compreender literatura", a hermenêutica do texto literário pode ser nomeada como "hermenêutica literária" (TAMEN, 1987, p. 15). Na opinião de Miguel Tamen:

Ainda que inventada por outros campos, tais como a teologia, o direito, a história e, por fim, a filosofia propriamente dita, a questão da interpretação tornou-se nos últimos

“[...] hermenêutica é somente um gênero proeminente que trata fundamentalmente de textos abertos ao entendimento. Mas quando se trata de interpretar algo que não é textual nem manuscrito, como cultura, entropia ou até o incomensurável, os procedimentos da interpretação estão destinados a mudar” (Tradução nossa).

"Interpretação é um ato de tradução, cuja execução depende do assunto a ser interpretado bem como do contexto no qual a atividade se realiza” (Tradução nossa). 
trinta anos uma preocupação proeminente das regiões fluidas da crítica e da teoria literárias, a ponto de, nalguns sítios, o seu destino se ter ligado ao destino da própria teoria literária e se ter tornado fonte de uma abundante literatura. (TAMEN, 1994, p. 09)

Devemos questionar, assim, o motivo que faz a hermenêutica ser tida como uma questão proeminente nos estudos literários, conforme Tamen alude em Maneiras da interpretação, livro concluído no fim da década de 1980.

Importa perceber como e por que variam tanto o que se define como sentido textual e o como se lê, quanto a compreensão do literário manifesta pelo crítico a partir dessa maneira. Ou seja, a maneira pela qual o crítico conduz o gesto hermenêutico traduzirá uma compreensão da literatura. Diante das variáveis através das quais esse gesto pode ser levado a cabo, é preciso que o crítico explicite a maneira como o entende, pois essa maneira molda e condiciona a compreensão do texto. É preciso haver uma reflexão meta-hermenêutica, uma reflexão que faça a descrição crítica dos pressupostos defendidos, até para que o resultado hermenêutico deixe de ser pensado num plano individual e tenha condição de ser legitimado.

O gesto hermenêutico é indissociável da análise do papel do leitor, pois ambos estão relacionados diretamente com o sentido e o texto, além de catalisarem influências de âmbito institucional, histórico-cultural, político ou teórico. A relação entre texto e leitor é necessariamente ladrilhada de sistemas valorativos, pois leitores definem posições quando leem e quando escolhem o livro a ser lido. Desse modo, a escolha dos textos a serem lidos deve ser observada, por aludir à manutenção de um cânone literário ou, até mesmo, de um cânone crítico.

Nos termos de José Manuel Cuesta Abad, podemos dizer que

[...] no existe creación literaria que no presuponga el concepto de comprensión: la actitud hermenéutica es la condición de posibilidad de la Literatura. En la obra literaria se hacen evidentes las exigencias de la comprensión, el lenguaje espejea en la densidad expresiva de sus constituyentes. Antes que nada, un poema o un relato requieren interpretación, y avisan de su requerimiento a través de una introversión del lenguaje, enfatizando ostensivamente sus pliegues y repliegues de signos. Así como el lenguaje experimenta en su doblez un extrañamiento, la interpretación se convierte en un juego especular, tematizándose, problematizándose en busca constante del sentido. (CUESTA ABAD, 1991, p. 11; grifo do autor)

O gesto hermenêutico junto ao enunciado literário ressalta o papel do leitor, por ser a leitura a condição de o texto ganhar vida - ou seja, adquirir sentido e valor -, motivo que faz a recepção ser um fator preponderante para se pensar a literatura. $O$ enunciado

“[...] não existe criação literária que não implique o conceito de compreensão: a atitude hermenêutica é a condição de possibilidade da Literatura. Na obra literária se tornam evidentes as exigências da compreensão, a linguagem reflete a densidade expressiva de seus constituintes. Primeiramente, um poema ou um relato requerem interpretação, e sinalizam sua demanda através de uma introversão da linguagem, enfatizando ostensivamente suas dobras e dobras de signos. Assim como a linguagem experimenta em sua dobra um estranhamento, a interpretação se converte num jogo especular, se programando e se problematizando numa busca constante pelo sentido" (Tradução nossa). 
literário não é prescritivo como o da lei civil, não está sujeito às verificações do método empírico como o científico e não é denotativo como o jornalístico ou o histórico ${ }^{5}$. Em contraste com textos que prezam uma verificabilidade de cunho pragmático, o enunciado literário compreende uma dimensão imagética, razão pela qual apresenta um referencial cuja topografia - de natureza ficcional - é imprecisa, por não se encontrar nem no texto, nem do lado de fora do texto.

Importante elemento caracterizador da literatura, o estatuto do ficcional gera o questionamento do referencial criado pelo texto literário, pois, ao mesmo tempo em que esse texto pode acolher o mundo real, ele cria um outro mundo possível, com elevada complexidade cognitiva. O estatuto do ficcional promove a dúvida quanto à realidade do objeto literário - espécie de objeto ausente - e problematiza a ideia segundo a qual a verdade do texto possa estar em correspondência com a realidade, colocando em xeque as certezas prévias do leitor. No entanto, conforme Iser teoriza, a literatura não escusa a realidade: "Como o texto ficcional contém elementos do real, sem que se esgote na descrição deste real, então o seu componente fictício não tem o caráter de uma finalidade em si mesma, mas é, enquanto fingida, a preparação de um imaginário” (ISER, 2002, p. 957). O imaginário distingue uma realidade não manifesta, que invalida preceitos substancialistas e que sublinha a fração de autonomia do leitor no processo interpretativo.

Assim, o sentido do referencial criado pelo texto literário não está alheio às interferências ou mediações presentes no ato da leitura, sejam elas de natureza empírica, axiológica, histórico-cultural, política ou teórica, motivo pelo qual esse referencial recusa uma fixação unívoca e perene. Portanto, o ficcional deve ser pensado, indissociavelmente, a partir de uma força centrífuga - que favorece a conexão com o mundo empírico, seja no processo de produção do texto, seja no de sua recepção - e de uma construção linguístico-formal, que remete para o desenho do texto. Ainda que possa haver o predomínio de uma dessas instâncias sobre a outra conforme o estilo do autor, o ficcional não comporta a distinção dicotômica entre uma visada realista e outra de cunho formal, diferentemente da compartimentação presente na ilusão romanesca depreendida por Marthe Robert a partir da história do romance:

Genericamente, e sem levar em conta inumeráveis formas transitórias, a ilusão romanesca pode ser tratada de duas formas: ou o autor faz como se ela não existisse em absoluto, e a obra passa por realista, naturalista ou simplesmente fiel à vida; ou exibe o como se que é sua principal intenção, e, nesse caso, a obra é dita onírica, fantástica, subjetiva, ou ainda classificada sob a rubrica mais ampla do simbólico. Há, portanto, dois tipos de romance, um que pretende haurir sua matéria no vivo para se tornar uma "fatia da vida" ou o famoso "espelho que desfilamos por um caminho"; outro, que, ao admitir previamente não passar de um jogo de formas e figuras, mantém-se quite com toda obrigação que não decorra imediatamente de seu projeto. Dos dois, naturalmente é o primeiro que engana mais solidamente, já que faz de tudo para escamotear a ilusão; além disso, chama atenção para o engodo do segundo, pois se o escrito e o vivo apresentam entre si não analogias, mas pura

Ver a tipologia dos enunciados - caracterizados em denotativo, performativo e prescritivo - proposta por Jean-François Lyotard, em A condição pós-moderna (2002, p. 15-19). 
e simplesmente graus de passagem que todo autor pode esperar transpor até o último, o romance de pura fantasia é necessariamente percebido como falso ou, no mínimo, como retrógrado no nível do puro entretenimento [...]. (ROBERT, 2007, p. 53; grifos da autora)

A se ratificar essa distinção, seria forçoso reconhecer que uns romances são mais verdadeiros e outros, com quimeras generosas, são totalmente falaciosos, o que certamente asseguraria um critério valorativo - cevado na identificação do real pelo leitor ou numa concepção de mundo autoevidente - dos mais duvidosos. Ora, como pensar, por exemplo, que o efeito de estranhamento criado por Kafka através da deformação do real e do deslocamento dos sentidos habituais pode ser taxado de infiel à vida?

Já na década de 1930, Günther Anders avalia Kafka como um escritor realista, no ensaio Kafka: pró \& contra: “[...] Kafka deslouca a aparência aparentemente normal do nosso mundo louco, para tornar visível sua loucura. Manipula, contudo, essa aparência louca como algo muito normal e, com isso, descreve até mesmo o fato louco de que o mundo louco seja considerado normal" (ANDERS, 2007, p. 15; grifo do autor). A se concordar com Anders, trata-se de frisar que há maneiras menos óbvias de um texto se apropriar do mundo real do que as concebidas pelo modelo de ficção realista stricto sensu, segundo o qual a obra deve estar próxima do contexto em que foi gerada, isto é, o referencial extraliterário pode ser transposto, em tese, para o texto literário, sem que sejam previstos, para tanto, processos deformativos e de desautomatização.

Conforme Marthe Robert lembra, o exemplo mais contundente da frenética sobreposição de configurações empreendida pela literatura e do desafio teórico daí decorrente reside na teoria do romance:

Tendo deixado o status de gênero menor e desacreditado a uma potência provavelmente sem precedente, ele [o romance] é agora praticamente único a reinar na vida literária [...]. Com essa liberdade do conquistador cuja única lei é a expansão indefinida, o romance, que aboliu de uma vez por todas as antigas castas literárias - as dos gêneros clássicos -, apropria-se de todas as formas de expressão, explorando em benefício próprio todos os procedimentos sem nem sequer ser solicitado a justificar seu emprego. E, paralelamente a essa dilapidação do capital literário acumulado por séculos, apodera-se de setores cada vez mais vastos da experiência humana, vangloriando-se de conhecê-la profundamente e da qual faz uma reprodução, ora apreendendo-a diretamente, ora interpretando-a à maneira do moralista, do historiador, do teólogo e, até mesmo, do filósofo e do cientista. [...] Gênero revolucionário e burguês, democrático por opção e animado por um espírito totalitário que o leva a romper obstáculos e fronteiras, o romance é livre, livre até o arbitrário e até o último grau de anarquia. (ROBERT, 2007, p. 12-13)

Vale ressaltar, porém, que as definições de Robert e de Mikhail Bakhtin - para quem o romance é "[...] um gênero que eternamente se procura, se analisa e que reconsidera todas as suas formas adquiridas" (BAKHTIN, 1990, p. 427) - apresentam uma visão idealizada de romance, uma vez que, por mais liberdade formal que o romance possa ter ou por mais longe que seus tentáculos consigam alcançar, trata-se de um gênero 
inexoravelmente realista. Segundo a orientação ampla do termo, o aludido "realismo" diz respeito aqui a categorias representacionais elementares - isto é, sujeito, tempo e espaço - das quais não se pode fugir. Apesar da ubiquidade dessas categorias, na sua acepção moderna, a literatura de ficção acentua a mudança no sistema operativo tanto da produção do texto literário como da sua recepção.

Considerando que a modernidade literária cria não só o problema hermenêutico ou seja, o do sentido do texto -, como também o engasgo na hora de se responder à pergunta “o que é literatura?”, é preciso relevar: ainda que a literatura não seja dada a comprovações e precise quase que de uma zona de indistinção entre o verdadeiro e o falso, desde o surgimento oficial da teoria da literatura como disciplina científica com os formalistas russos - e poderíamos lembrar também os fragmentos de Schlegel e de Novalis -, o impasse sobre o sentido textual e a definição do literário é permanente e molda uma polarização entre as diversas perspectivas teóricas.

Entre elas, umas garantem uma maior asserção de sentido, como a teoria sociológica, e outras relativizam essa asserção, como as estéticas da recepção e do efeito, ao associarem a poética da ficção a uma poética da negatividade. Mesmo que a preocupação com o sentido textual seja uma constante entre as perspectivas teóricas, curiosamente, no traçado histórico percorrido por elas, constatamos que o leitor ficou no limbo dos estudos literários durante um bom tempo, pois o rigor científico que se pretendia no estudo da literatura ficaria abalado ao se avaliar positivamente o papel do leitor, já que essa avaliação implicaria admitir que o sentido sofre a interferência de variáveis e de fatores incertos.

A hermenêutica literária demonstra, por conseguinte, a urdidura de um enunciado que convoca, na sua leitura, as mais heterogêneas e incompatíveis perspectivas históricas, críticas e teóricas. Essa diversidade pode ser exemplarmente demonstrada nos estudos críticos sobre a obra de Kafka, que sofrem influência das teorias estruturalista, existencialista, marxista, freudiana, heideggeriana, desconstrucionista, entre outras. Dessa maneira, é preciso pôr em relevo o sujeito que interpreta (o leitor), como também os procedimentos metodológicos junto aos quais se interpreta.

Ao falar sobre a obra de Kafka no ensaio "Anotações sobre Kafka", Theodor Adorno evoca a tensão que deve haver no ato da leitura, fundamento para seu desagrado perante frames que inserem Kafka em ordens preestabelecidas, como o existencialismo, tônica da recepção à obra do autor até então. Para Adorno, desde que enfatizados "os aspectos que dificultam o enquadramento" (ADORNO, 2001, p. 239), a demanda da obra por interpretação teria o devido destaque. Ainda que essa demanda seja inerente ao enunciado literário, sem que se façam distinções, a obra kafkiana vale como uma baliza, pois parece importante identificar em certos autores ou obras a razão pela qual a hermenêutica coloca-se como questão metateórica. Assim, vislumbra-se um caminho para se explicar por que determinados autores ou obras incitam uma recepção crítica mais caudalosa e diversificada, em termos comparativos, quanto ao seu sistema teórico-metodológico.

A complexidade da questão pertinente à hermenêutica literária faz com que Adorno defenda posições um pouco ambíguas: 
As criações de Kafka se protegem do erro artístico mortal que consiste em crer que a filosofia que o autor injeta na obra seja o seu teor metafísico. Se fosse assim, a obra teria nascido morta: ela se esgotaria naquilo que diz e não se desdobraria no tempo. Para se prevenir contra o curto-circuito causado pelo sentido prematuro já visado pela obra, a primeira regra é tomar tudo literalmente, sem recobrir a obra com conceitos impostos a partir de cima. A autoridade de Kafka é a dos textos. Somente a fidelidade à letra pode ajudar, e não a compreensão orientada. Em uma escrita que continuadamente obscurece e esconde o que quer dizer, todo enunciado determinado contrabalança a cláusula geral da indeterminação. (ADORNO, 2001, p. 242; grifos nossos)

O que o filósofo propõe como "princípio de literalidade" (ADORNO, 2001, p. 242) sugere um imperativo kafkiano do não interpretar. Contudo, no decorrer do referido ensaio, Adorno apresenta várias determinações semânticas à obra de Kafka. Ainda que sob a dificuldade de um texto que simula a explosão do sentido, é insustentável defender que tal "princípio de literalidade" não esconde um gesto hermenêutico.

A ambiguidade observada na argumentação de Adorno expressa o problema fulcral em torno da hermenêutica literária por mostrar como o sentido do texto está sempre pendente e, assim, como a atribuição e a produção desse sentido não se realizam sem a interferência de valores exteriores ao texto e sem a criação de um discurso paralelo ao texto que inviabiliza tal literalidade. A participação do intérprete parece, entretanto, estar contemplada nas preocupações de Adorno, na medida em que o filósofo prevê o esforço do leitor para compreender a obra:

A violência com que Kafka reclama interpretação encurta a distância estética. Ele exige do observador pretensamente desinteressado um esforço desesperado, agredindo-o e sugerindo que de sua correta compreensão depende muito mais que apenas o equilíbrio espiritual: é uma questão de vida ou morte. (ADORNO, 2001, p. 241)

No romance $O$ processo, o espaço é construído enquanto desestabilização: um espaço móbile, por se fazer, desfazer e refazer repetidamente como se ocupasse a mesma base, sendo condição para ser refeito a desconstrução do que antes a ocupava, à maneira de um espaço cênico. K., o protagonista, não consegue conceber uma visão do todo espacial onde circula. O mesmo ocorre com o leitor, que acompanha a trajetória da personagem admirado com os desdobramentos de signos que lhe são caros no mundo efetivo - como pensão, tribunal, cartório, banco, catedral -, mas que, no romance, recebem um tratamento que privilegia o deslocamento e a exterioridade. Por esse motivo, o espaço não se instaura nem em termos definidos, nem, muito menos, definitivos, o que impede uma correspondência funcional, frustrando as expectativas de K.

Atentamos para a desrealização espacial que assola K. nas cenas em que se encontra no cartório e na catedral. Nessas cenas, K. manifesta sua desorientação, numa demonstração de que a cartografia espacial ganha nuances específicas para essa personagem, próximas de uma denotação labiríntica. Ainda que se perceba uma forma concisa e um "sistema lógico" (ADORNO, 2001, p. 252) operante, há, em contrapartida, uma inexauribi- 
lidade do sentido como força motriz. Essa denotação labiríntica associa-se também ao próprio processo: "não era impossível que [K.] recebesse da parte dele [do sacerdote] um conselho decisivo e aceitável, que lhe mostrasse, por exemplo, não como o processo talvez pudesse ser influenciado, mas sim como se poderia sair dele, como se poderia contorná-lo, como se poderia viver fora dele" (KAFKA, 1997, p. 260; grifos nossos).

O processo significa, habitualmente, a materialidade de um caderno com capa e folhas ajuntadas, mas, nesse caso, exprime uma dimensão espacial, que reitera a obscuridade e o tortuoso, impressões de K. para lugares empiricamente espaciais. Mediante essa "realidade" processual, paralela e sinuosa, surge uma série de questionamentos quanto à veracidade inspirada por ela e ao seu sentido. Podemos pensar que o romance conduz a uma discussão sobre o modo como percebemos e validamos os referenciais do mundo, pois, ao longo das suas páginas, vemos uma sucessão de comentários reveladores do artifício como liga mestra do mundo ${ }^{6}$, válidos, de maneira análoga, para a teoria da ficção.

Tentamos uma aproximação entre a problemática quanto à "verdade" do processo para K. e o tipo de "pacto" caro ao leitor de literatura com o objetivo de atentarmos para as aporias hermenêuticas que o enunciado literário provê. O desenvolvimento da narrativa de $O$ processo tem seu ponto crucial no capítulo "Na catedral", que apresenta uma relativização num nível paroxístico. A título de exemplo, lembramos o momento em que o sacerdote alude à "interpretação" dos deveres cumpridos pelo porteiro nos "textos introdutórios à lei”: "A compreensão correta de uma coisa e a má compreensão dessa mesma coisa não se excluem completamente" (KAFKA, 1997, p. 265). O capítulo propõe uma demonstração cerrada da vertigem em que consistem a atribuição e a produção de sentido, isto é, o quanto a asseveração de um referencial é tergiversa, tendo em vista a pulverização hermenêutica a que um mesmo texto está sujeito. Como o sacerdote explica a K.: "Você não precisa dar atenção demasiada às opiniões. O texto é imutável, e as opiniões são muitas vezes apenas uma expressão de desespero por isso" (KAFKA, 1997, p. 266). No romance, a ironia - latente, relacionada à decidibilidade do sentido - é revelada através de uma composição eminentemente espacial. O espaço interditado desnuda a ignorância constitutiva do conhecimento, sempre por vir, mas, no entanto, irremediável.

Apesar das discordâncias existentes no âmbito da literatura, a hermenêutica pode ser vista a partir de alguns pontos comuns, que, admitidos como exemplo e hipoteticamente, são organizados em torno do estímulo e do obstáculo à compreensão e à interpretação do texto. Conjeturamos que a maneira como se entende a hermenêutica literária é congruente com sistemas de legibilidade do mundo e com teorias da subjetividade, que se apresentam junto à hermenêutica, ou seja, junto a reflexões teóricas sobre a compreensão da literatura, sobre as relações e possibilidades admitidas no processamento do texto. Conjeturamos também que, ao se produzir sentido, conceitos e teorias são necessariamente deduzidos, bem como valores, inferências culturais, sócio-históricas e políticas - e deduções como essas já regulam e controlam a compreensão e a interpretação do texto, pois elas impõem uma série de negociações semânticas.

6 No ensaio que escreve sobre Kafka, Walter Benjamin aponta para essa direção ao afirmar que "[o] mundo de Kafka é um teatro do mundo. Para ele, o homem está desde o início no palco” (BENJAMIN, 1994, p. 150). 
Importa avaliar se os percalços encontrados no processamento do texto são revertidos em alguma espécie de benesse e se acarretam questões específicas. Quanto ao primeiro ponto, podemos admitir, por exemplo, a hipótese segundo a qual uma escrita como a de Kafka desencadeia um questionamento do sentido, que, no seu desenvolvimento, instiga o leitor a analisar o mundo em que vive. Nesse caso, sob o estranhamento motivado pelo estilo kafkiano, o leitor pode ser provocado a impugnar as relações de poder e autoridade que estão à sua volta. Isto é, a partir do esforço que, em tese, o leitor dedica ao entendimento de uma literatura marcada pela negatividade como a de Kafka, poderá haver uma chance maior de se fazer da leitura de um texto, que cria um mundo nada familiar, a devida oportunidade de inflexão num cotidiano costurado normalmente sob rotina, atitudes e pensamentos mecânicos. Quanto ao segundo ponto, podemos admitir que, num texto em que os obstáculos ao sentido - como exemplificam as lacunas textuais - sejam mais protuberantes, a doação de sentido, maneira de solver esses obstáculos, poderá ser feita em diferentes níveis e de diferentes maneiras, o que faz esse texto ser mais polivalente do que outros.

\section{Referências Bibliográficas}

ADORNO, T. “Anotações sobre Kafka”. In: Prismas: crítica cultural e sociedade.

Trad. Augustin Wernet e Jorge Mattos Brito de Almeida. São Paulo: Ática, 2001.

ANDERS, G. Kafka: pró \& contra - os autos do processo. Trad., posf. e notas: Modesto Carone. São Paulo: Cosac Naify, 2007.

BAKHTIN, M. "Epos e romance (sobre a metodologia do estudo do romance)". In:

Questões de literatura e de estética: a teoria do romance. Trad. Aurora F. Bernardini et. al. São Paulo: UNESP; HUCITEC, 1990.

BENJAMIN, W. Franz Kafka: a propósito do décimo aniversário de sua morte. In:

Magia e técnica, arte e política: ensaios sobre literatura e história da cultura. Trad. Sérgio Paulo Rouanet. São Paulo: Brasiliense, 1994.

COSTA LIMA, L. Limites da voz: Kafka. Rio de Janeiro: Rocco, 1993.

CUESTA ABAD, J. Teoría hermenéutica y literatura (el sujeto del texto). Madrid: Visor, 1991. GUMBRECHT, H. “O campo não-hermenêutico ou a materialidade da comunicação”. In: . Corpo e forma: ensaios para uma crítica não-hermenêutica. Org. João Cezar de Castro Rocha. Rio de Janeiro: EdUERJ, 1998.

ISER, W. $O$ ato da leitura: uma teoria do efeito estético. Trad. J. Kretschmer. São Paulo: Ed. 34, 1996. 2 v.

. "Os atos de fingir ou o que é fictício no texto ficcional”. In: COSTA LIMA, Luiz (Org.). Teoria da literatura em suas fontes. Rio de Janeiro: Civilização Brasileira, 2002. v. 2. The range of interpretation. New York: Columbia University Press, 2000.

KAFKA, F. O castelo. Trad. e posfácio: Modesto Carone. São Paulo: Companhia das Letras, 2000. . O processo. Trad. e posfácio: Modesto Carone. São Paulo: Companhia das Letras, 1997. . “Uma mensagem imperial”. In: KAFKA, F. Um médico rural: pequenas narrativas.

Trad. e posfácio: Modesto Carone. São Paulo: Companhia das Letras, 1999. 
LYOTARD, J. A condição pós-moderna. Trad. Ricardo Corrêa Barbosa. Rio de Janeiro: José Olympio, 2002.

ROBERT, M. Romance das origens, origens do romance. Trad. André Telles. São Paulo: Cosac Naify, 2007.

TAMEN, M. Hermenêutica e mal-estar. Lisboa: Imprensa Nacional, 1987.

. Maneiras da interpretação: os fins do argumento nos estudos literário. Lisboa: Imprensa Nacional, 1994.

ArTigo ReCEBIDO EM: 18 ago. 2012

ARTIGO ACEITO EM: 12 set. 2012

ReferênCIA ELETRÔNiCA: ROCHA, Janine Resende. O espaço da ficção e os limites do sentido. Revista Criação \& Crítica, n. 9, p. 61-71, nov. 2012. Disponível em: <http://www.revistas.usp.br/criacaoecritica>. Acesso em dd mmm aaaa. 